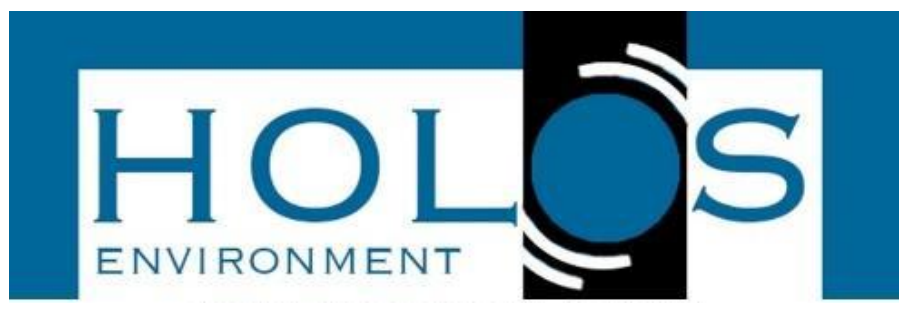

\title{
ESTABILIZAÇÃO/SOLIDIFICAÇÃO: CARACTERIZAÇÃO, CLASSIFICAÇÃO E APLICAÇÃO NO TRATAMENTO E GERENCIAMENTO DE RESÍDUOS SÓLIDOS DE LABORATÓRIOS QUÍMICOS
}

\section{STABILIZATION / SOLIDIFICATION: CHARACTERIZATION, CLASSIFICATION AND APPLICATION IN THE TREATMENT AND MANAGEMENT OF SOLID RESIDUE FROM CHEMICAL LABORATORIES}

\author{
Josevânia Rodrigues Jovelino; André Luiz Fiquene de Brito; Ana Cristina da Silva Muniz; \\ Poliana Pinheiro da Silva ${ }^{3}$
}

Artigo recebido em: 16/07/2020 e aceito para publicação em: 14/08/2020.

DOI: http:/dx.doi.org/10.14295/holos.v20i4.12410

Resumo: As instituições de ensino superior representam um problema relacionado ao tratamento e disposição final dos resíduos gerados em seus laboratórios. Dessa forma, o objetivo desse estudo é aplicar a técnica de estabilização/solidificação no tratamento de Resíduos Sólidos de Laboratórios químicos (RSL) visando proporcionar o seu descarte adequado. Os ensaios consistem na caracterização e classificação dos materiais utilizados (RSL, cimento, areia e brita). Foi aplicado o planejamento experimental one-way com três repetições. $O$ fator avaliado foi a porcentagem de resíduos sólidos do laboratório (10, 30 e 45\%) e através dos experimentos, foi possível observar as seguintes variáveis de resposta: Resistência à Compressão $(R C)$, Capacidade de Absorção de Água (CAA), Umidificação/Secagem (U/S) e Lixiviação. Por fim, foi realizada a análise estatística dos dados, o balanço de massa e o cálculo da eficiência de retenção dos metais pesados cádmio e níquel na matriz de cimento. Todos os tratamentos foram aprovados nos testes RC, CAA, U/S. O resíduo avaliado permaneceu na Classe I (Perigoso), no entanto, todos os tratamentos realizados apresentaram eficiência de retenção dos metais pesados cádmio e níquel acima de $98 \%$, indicando que a estabilização/solidificação é uma opção viável para atenuar a quantidade de metais pesados presentes em resíduos sólidos de laboratórios químicos.

Palavras-chave: Resíduo sólido. Lixiviação. Balanço de massa. Eficiência.

Abstract: Higher education institutions represent a problem related to the treatment and final
disposal of waste generated in their laboratories. Thus, the objective of this study is to apply the
stabilization / solidification technique in the treatment of solid waste from chemical laboratories (RSL)
in order to provide its proper disposal. The tests consist of the characterization and classification of
the materials used (RSL, cement, sand and gravel). One-way experimental planning with three
replications was applied. The evaluated factor was the percentage of solid waste from the laboratory
(10, 30 and $45 \%)$ and through the experiments, it was possible to observe the following response

\footnotetext{
${ }^{1}$ Universidade Federal de Campina Grande (UFCG), Campina Grande, PB, Brasil. E-mails: (vannya.req@gmail.com, andre@deq.ufcg.edu.br, anamuniz@deq.ufcg.edu.br)

2 Universidade Federal do Rio Grande do Norte (UFRN), Natal, RN. E-mail: (poli anapinheiro@hotmail.com)
} 
variables: Compression Resistance (RC), Water Absorption Capacity (CAA), Humidification / Drying $(\mathrm{U} / \mathrm{S})$ and Leaching. Finally, statistical analysis of the data, mass balance and calculation of the retention efficiency of heavy metals cadmium and nickel in the cement matrix was performed. All treatments passed the RC, CAA, U / S tests. The evaluated residue remained in Class I (Dangerous), however, all treatments carried out showed efficiency of retention of heavy metals cadmium and nickel above $98 \%$, indicating that stabilization / solidification is a viable option to attenuate the amount of heavy metals present in solid waste from chemical laboratories.

Keywords: Solid waste. Leaching. Mass balance. Efficiency.

\section{INTRODUÇÃO}

Embora as indústrias sejam responsáveis pela geração da maior parcela de resíduos químicos, a presença desse tipo de resíduo não se limita apenas a elas. Os laboratórios de universidades, escolas e instituições de pesquisa também são responsáveis pela geração de resíduos com grande diversidade e volume reduzido. Muitos desses resíduos são jogados diretamente na pia, o que dificulta a realização de um monitoramento real do volume de resíduos químicos gerados pelo laboratório (LIMA et al., 2016; IMBRIOSE et al., 2006).

Um projeto de gerenciamento de resíduos é capaz de reduzir riscos e tornar o local de trabalho menos prejudicial e perigoso, além de incentivar estudantes, técnicos e professores a descartar adequadamente o lixo gerado em sua instituição e que pode representar um grande risco à saúde e ao meio ambiente, se não adequadamente gerenciados. Entre esses resíduos químicos, encontram-se produtos hormonais, citostáticos, desinfetantes, além de reagentes químicos contendo metais pesados (LOZOVEY; SCHNEIDER, 2014).

A Estabilização por Solidificação (E/S) surge como uma alternativa viável para o tratamento e disposição de resíduos sólidos. É um procedimento que tem a capacidade de converter resíduos tóxicos para uma forma física e quimicamente mais estáveis, ou seja, modifica quimicamente resíduos perigosos a fim de se obter uma forma menos tóxica destes. Este processo permite reduzir a mobilidade de espécies nocivas ao meio ambiente e aos seres vivos, reduzindo a mobilidade e lixiviação desses contaminantes para o meio (WANG et al., 2018).

A técnica de E/S é capaz de solidificar, insolubilizar, imobilizar, encapsular, destruir ou interagir com os componentes dos resíduos utilizados por meios químicos, obtendo 
sólidos não perigosos ou menos perigosos que os resíduos originais. Consiste na combinação de dois processos que ocorrem ao mesmo tempo para obter um produto que causa menor impacto ambiental quando descartado ou reutilizado (RAMOS et al., 2009).

No processo de solidificação/estabilização, normalmente é utilizado um fixador (aglomerante) como agente solidificante. Os principais aglomerantes utilizados são: cimento Portland, cal, asfalto, polímero, etc. Entre esses, o mais utilizado é o cimento Portland, pois as reações químicas são ativadas apenas pela água (reações de hidratação), ocorrendo à temperatura ambiente e seu endurecimento (aderência), o que leva à formação de uma microestrutura sólida em algumas horas (BREHM et al., 2013). A (E/S) vem apresentando-se como uma tecnologia eficiente e confiável para o tratamento de materiais perigosos (CHEN et al., 2019).

Sabe-se que toda entrada de matéria deve encontrar uma saída quantificada no produto, subprodutos e resíduos sólidos, líquidos e gasosos. Nesse contexto, é importante realizar o balanço de massa do processo, cujo objetivo é quantificar as massas de resíduos sólidos de laboratório antes e depois do tratamento pelo processo de estabilização por solidificação.

Consiste em uma descrição dos fluxos de massa que entram e saem do sistema e vale ressaltar que o balanço de massa deve ser complementado com outras informações sobre os produtos utilizados, tais como: propriedades físico-químicas, toxicidade, perigo e potencial de evolução (AQUIM; BRITO \& SOARES, 2009).

O objetivo deste trabalho é realizar o tratamento de resíduos sólidos de laboratórios químicos a partir do processo de Estabilização/Solidificação e avaliar a eficiência do processo na retenção de contaminantes no interior da matriz cimentícea obtida, além de definir rotas de destinação adequada para o material após passar pelo tratamento.

\section{MATERIAL E MÉTODOS}

\subsection{Planejamento experimental e análise estatística dos dados}

Neste estudo, a análise de regressão foi aplicada ao planejamento one-way. O planejamento one-way é aquele em que existe apenas um fator de interesse. A regressão na análise de variância é uma técnica estatística para modelar e investigar a relação entre 
variáveis dependentes e preditoras. Um modelo de regressão que contém um ou mais de um regressor é chamado de modelo de regressão linear (MONTGOMERY \& RUNGER, 2003).

A regressão testa se os termos do modelo têm algum efeito na resposta, testa o linear, o quadrático e a interação. Os termos quadráticos indicam se há ou não curvatura (quadrática) na superfície de resposta. $O$ erro (residual) mede quanto da variação da resposta não é explicada pelo modelo. Essa variação é subdividida em duas partes: falta de ajuste (é a variação devido à inadequação do modelo) e erro puro.

Neste trabalho, a porcentagem de resíduo sólido de laboratório (\% RSL) foi usada como fator de interesse e as respostas avaliadas foram: Capacidade de Absorção de Água (CAA), Resistência à Compressão (RC), Umidificação/Secagem (U/S) e Lixiviação. A Tabela 1 mostra o fator utilizado na pesquisa, a porcentagem de RSL, a quantidade de resíduos sólidos de laboratório, a quantidade de cimento, o volume de água, a massa de areia e a massa de brita. O tempo de cura foi estabelecido em 28 dias. Os metais analisados foram cádmio e níquel. Na pesquisa, foram realizadas três repetições.

Tabela 1 - One-Way: planejamento experimental

\begin{tabular}{cccccc}
\hline $\begin{array}{c}\text { \%RSL } \\
\text { (fator) }\end{array}$ & $\begin{array}{c}\text { Massa de RSL } \\
\text { (g) }\end{array}$ & $\begin{array}{c}\text { Massa de } \\
\text { cimento } \\
\mathbf{( g )}\end{array}$ & $\begin{array}{c}\text { Massa de } \\
\text { areia } \\
(\mathbf{g})\end{array}$ & $\begin{array}{c}\text { Massa de } \\
\text { brita }(\mathbf{g})\end{array}$ & $\begin{array}{c}\text { Volume de } \\
\text { água } \\
\text { (mL) }\end{array}$ \\
\hline 0 & 0,0 & 75,0 & 262,5 & 112,5 & 60 \\
0 & 0,0 & 75,0 & 262,5 & 112,5 & 60 \\
0 & 0,0 & 75,0 & 262,5 & 112,5 & 60,0 \\
10 & 7,5 & 75,0 & 255,0 & 112,5 & 60,0 \\
10 & 7,5 & 75,0 & 255,0 & 112,5 & 60,0 \\
10 & 7,5 & 75,0 & 255,0 & 112,5 & 60,0 \\
30 & 22,5 & 75,0 & 240,0 & 112,5 & 60,0 \\
30 & 22,5 & 75,0 & 240,0 & 112,5 & 60,0 \\
30 & 22,5 & 75,0 & 240,0 & 112,5 & 60,0 \\
45 & 33,8 & 75,0 & 228,8 & 112,5 & 60,0 \\
45 & 33,8 & 75,0 & 228,8 & 112,5 & 60,0 \\
45 & 33,8 & 75,0 & 228,8 & 112,5 & 60,0 \\
\hline
\end{tabular}

\% RSL: Porcentagem de resíduo sólido de laboratório; Massa de RSL: massa de resíduo sólido de laboratório.

Fonte: Elaborado pelos autores.

A verificação do modelo proposto de regressão linear foi realizada de acordo com a recomendação de Montgomery e Runger (2003), por meio do teste estatístico de hipóteses em relação aos parâmetros do modelo. Essas hipóteses foram observadas quanto à significância da regressão, onde a hipótese nula $\left(H_{0}: \beta_{1}=0\right)$ equivale a concluir que não há 
relação linear entre $x$ (porcentagem de resíduo de laboratório) e $Y$ (resposta). A hipótese alternativa $\left(H_{1}: \beta_{1} \neq 0\right)$ é equivalente a afirmar que existe uma relação linear entre $x$ (porcentagem de resíduo de laboratório) e $Y$ (resposta), ou seja, o valor esperado de $Y$ é afetado pelos valores de $\mathrm{x}$.

$\mathrm{O}$ teste $\mathrm{F}$ e/ou o teste $\mathrm{P}$ foram aplicados através da ANOVA para comparar as médias. Se o valor de $P \leq 0,05$, as médias dos tratamentos são diferentes, ou seja, houve efeito do fator e a variável controlável influenciou na variável resposta. Se o valor de P> 0,05, as médias de tratamento não são diferentes. Ou seja, não haverá efeito do fator e a variável controlável não influenciará a variável de resposta.

Neste trabalho, foi adotada uma probabilidade (nível de significância) de $\alpha=0,05$ (5\%). Assim, a relação linear entre a variável aleatória (variável dependente y) e a variável não aleatória (variável independente x) é descrita pela Equação (1).

$y=\beta_{0}+\beta_{1} x+\varepsilon$

Onde, $\beta_{0}$ e $\beta_{1}$ são os parâmetros do modelo; $(\varepsilon)$ é o erro aleatório associado à determinação de y; y representa a resposta; $x$ é a porcentagem de resíduo sólido de laboratório.

O coeficiente de determinação $R^{2}$, Equação (2), representa a variação que pode ser explicada pelo modelo, ou seja, quanto o modelo explica a variação nos dados usando os regressores $\mathrm{x}_{1}, \mathrm{x}_{2}, \ldots \mathrm{x}_{\mathrm{k}}$.

$R^{2}=\frac{S Q R}{S Q T}$

Onde, SQR é a soma dos quadrados da regressão; SQT é a soma dos quadrados totais.

A porcentagem máxima de variação explicável é calculada usando a Equação (3). Representa a variação máxima que o modelo explica. Este valor deve ser comparado com o valor explicado pelo modelo $\left(R^{2}\right)$.

$R_{\text {max }}^{2}=\frac{S Q_{\text {Total }}-S Q_{\text {erro_puro }}}{S Q_{\text {Total }}}$ 
Foi utilizado o software Minitab 17.0, que incorpora uma série de rotinas de manipulação de dados, análise de confiabilidade, gráficos e análises estatísticas (MINITAB 17.0, 2014). A Tabela 2 mostra a saída computacional do Minitab17.0 para a análise de regressão.

Tabela 2 - Análise de variância (ANOVA)

\begin{tabular}{lcccc}
\hline Fonte & $\begin{array}{c}\text { Soma do Quadrado } \\
\text { (SQ) }\end{array}$ & $\begin{array}{c}\text { Quadrado Médio } \\
(\mathbf{Q M})\end{array}$ & $\begin{array}{c}\text { Valor de } \mathbf{F} \\
\text { Regressão }\end{array}$ SSR & $\begin{array}{c}\text { Valor de } \mathbf{p}^{\mathbf{1}} \mathbf{e} \\
\mathbf{p}^{2}\end{array}$ \\
\hline Resíduo & SSE & MSE & MSR/MSE & - \\
Total & SST & - & - & \\
\hline
\end{tabular}

Valor $\mathrm{p}^{1}$ : Significativamente diferente ( $\left.\mathrm{p} \leq 0.05\right)$; Valor $\mathrm{p}^{2}$ : Não significativo ( $\left.p>0.05\right)$;

Fonte: Minitab, 2014.

\subsection{Caracterização e classificação do RSL, cimento, areia e brita}

O RSL utilizado foi coletado nos laboratórios de Química Geral e Química Analítica do curso de Engenharia Química, pertencente à Universidade Federal de Campina Grande, no campus localizado na cidade de Campina Grande, Paraíba. O aglomerante utilizado no processo de E/S foi o Cimento Portland CPII - Z32 da Elizabeth, o qual apresenta como resistência à compressão de $32 \mathrm{MPa}$ garantidos após 28 dias de tempo de cura.

O resíduo, o cimento e os aglomerantes foram caracterizados em termos de suas características iniciais como, teor de sólidos e suas frações (APHA, 1998), umidade (APHA, 1998) e pH (WTC, 1991). A classificação deste resíduo foi realizada através da determinação de metais a partir do extrato lixiviado e/ou solubilizado (ABNT NBR 10.005, 2004a; ABNT NBR 10.005, 2004b; ABNT NBR 10.006, 2004c).

\subsection{Confecção dos corpos de prova}

Os corpos de prova foram preparados seguindo as etapas propostas pela NBR 7215 (ABNT, 1996) e o Protocolo de avaliação de materiais E/S (BRITO, 2007). Para descobrir a percentagem \% adequada de RSL para aplicação da E/S foram realizados testes preliminares visando classificar e caracterizar o material.

A preparação dos corpos de prova (CP) foi realizada utilizando-se dos seguintes constituintes: cimento Portland CP II - Z32, areia fina, brita, RSL e água, em proporções 
para corpos de prova (CP) de $450 \mathrm{~g}$ e obedecendo a um traço de 1:5, mantendo-se constante o tempo de cura de 28 dias e variando a porcentagem de resíduo. O RSL e os demais constituintes foram pesados, separadamente, em uma balança analítica com precisão de 0,01 $\mathrm{g}$.

Após a pesagem individual dos constituintes, os mesmos foram homogeneizados em presença de água de modo a favorecer a reação química do cimento, obtendo uma massa homogênea. $O$ interior dos moldes foi devidamente lubrificado com óleo mineral visando facilitar o desmolde do corpo de prova. Em seguida, a massa homogênea das matrizes cimentícias foi colocada no interior dos moldes cilíndricos, em camadas compactadas para evitar a formação de espaços vazios no corpo de prova. Placas de vidro de $70 \mathrm{~mm}$ por 70 $\mathrm{mm}$ de aresta e $5 \mathrm{~mm}$ de espessura, foram lubrificadas com óleo mineral, e colocadas na superfície dos moldes, para evitar a perda de água ocasionada por evaporação.

O material ficou em repouso por um período de 24 horas para o endurecimento da pasta. Por fim, após o período de 24 horas, os corpos de prova foram desmoldados e curados para finalmente serem realizados os ensaios referentes aos critérios de integridade e durabilidade e imobilização após o tempo de cura.

\subsection{Integridade e durabilidade do material E/S}

De acordo com a ABNT - NBR 7215/1996 os critérios de integridade e durabilidade incluem: Ensaio de Resistência à Compressão (RC); Capacidade de Absorção de Água (CAA); Umidificação e Secagem (U/S).

\subsubsection{Resistência à Compressão}

O ensaio de resistência à compressão (RC) foi realizado conforme ABNT (1996) NBR 7215, para verificar a capacidade do material E/S em resistir a diferentes cargas de compressão mecânica. Neste ensaio foram utilizadas matrizes cimentíceas cilíndricas de $50 \mathrm{~mm}$ de diâmetro e $100 \mathrm{~mm}$ de altura. Cada uma delas foi posta diretamente sobre o prato inferior de uma prensa de modo a ficar rigorosamente centrado em relação ao eixo de carregamento. O parâmetro RC será calculado mediante a Equação (4), em kgf/cm², 
onde será obtido dividindo a carga de ruptura pela área da seção do corpo de prova (ABNT NBR 7215, 1996).

$$
R C=\frac{F}{A}
$$

Através da resistência mecânica do material E/S pode-se definir a rota de destinação do material E/S. Este pode ser utilizado para: execução de obras de alvenaria sem função estrutural, material de cobertura, pavimentação em obras de rodovias, uso em cerâmica vermelha (tijolos maciços, blocos cerâmicos e telhas) e fabricação de artefatos de concreto.

\subsubsection{Capacidade de Absorção de Água}

O ensaio de Capacidade de Absorção de Água (CAA) será realizado conforme a NBR 9778 ABNT (1987), cujo objetivo é a determinação da absorção de água, índice de vazios e massa específica, que avalia a porosidade do material endurecido ou E/S. Inicialmente os corpos de prova foram pesados e em seguida levados à estufa a $105^{\circ} \mathrm{C}$ por 24 horas. Posteriormente as amostras eram retiradas da estufa, pesadas e imersas em água a 23ํㅡ por ciclos de 24, 48 e 72 horas, as quais eram retiradas da água, enxugadas com papel absorvente, pesadas e imersas na água a cada ciclo.

Cinco horas antes de se completar o período de 72 horas de saturação em água, as amostras foram progressivamente levadas à ebulição na placa aquecedora até $100^{\circ} \mathrm{C}$. Em seguida, deixou-se resfriar, pela perda natural de calor até temperatura ambiente e foi feita a última pesagem. O resultado, portanto, foi expresso em \%, Equação (6), conhecendo-se a massa do corpo de prova após saturação em água e a massa do corpo de prova seca em estufa.

$C A A=\frac{M_{\text {sat }}-M_{\text {seca }}}{M_{\text {seca }}} \times 100$

Conforme Brito (2007), para ser aprovado no ensaio de capacidade de absorção de água e considerado como material E/S, a CAA obtida não pode exceder $40 \%$. 


\subsubsection{Umidificação e Secagem}

O ensaio de umidificação/secagem é utilizado para simular e avaliar o material resultante do procedimento de $\mathrm{E} / \mathrm{S}$, em relação à sua capacidade em resistir às variações de mudanças de estado, visando avaliar a durabilidade em longo prazo e a perda de massa após sucessivos períodos de umidificação/secagem.

O método consiste em pesar os corpos de prova que serão submetidos a seis ciclos da seguinte forma: umidificação com água deionizada, na proporção 2:1 em relação à massa da amostra natural; secagem em estufa a temperatura de $80^{\circ} \mathrm{C}$ por 24 horas para evaporação total da água; resfriamento em dessecador e pesagem (Pciclo i). Através da Equação (7) calculou-se a perda de peso da amostra após os 6 ciclos (BRITO, 2007).

Perda de peso $(\%)=\frac{P_{\text {nat }}-P_{\text {cycle }}}{P_{\text {nat }}} \times 100$

Onde, Pnat $=$ Peso da amostra natural; Pciclo i $=$ Peso da amostra após ciclo de umidificação/secagem.

\subsection{Lixiviação}

O ensaio de lixiviação foi utilizado para avaliar a imobilização dos contaminantes, ou seja, avaliar o potencial do resíduo em liberar contaminante para o meio ambiente. Foi avaliado o extrato lixiviado resultante do aglomerante, do RSL, da areia e das matrizes cimentíceas. Para a realização do ensaio de lixiviação, $100 \mathrm{~g}$ de uma amostra foi colocada em um frasco de $2000 \mathrm{ml}$ com água destilada, isenta de matéria orgânica mais a solução lixiviante (ácido acético glacial e água). A solução foi submetida à agitação em equipamento rotativo com 30 rotações por minuto por um período de $18 \pm 2$ horas.

\subsection{Eficiência de retenção dos contaminantes}

A eficiência do processo de Estabilização por Solidificação foi calculada com o objetivo de avaliar e comparar as massas dos agentes que influenciaram na eficiência de retenção dos contaminantes (BRITO, 2007): 
$X_{E R \%}=\left[1-\left(1+\frac{M R S L(\text { Bruto })}{M C P C}\right) \times\left(\frac{[y] \text { Tratado }}{[\text { z }] \text { Bruto }}\right)\right] x 100$

Onde, $X_{E R} \%$ é a eficiência de retenção dos contaminantes (\%); MRSL (bruto) é a massa do contaminante presente no RSL bruto (sem tratamento) $(\mathrm{kg})$; MCP é a massa do cimento Portland comum (kg); [y] Tratado é a concentração do contaminante após o tratamento por $\mathrm{E} / \mathrm{S}$ (mg.kg-1); [z] Bruto é a concentração do contaminante antes do tratamento por E/S $\left(\mathrm{mg} \cdot \mathrm{kg}^{-1}\right)$.

\subsection{Balanço de massa do processo de E/S}

O balanço de massa foi realizado para os contaminantes Níquel e Cádmio, visando determinar a atenuação em cada tratamento após a estabilização por solidificação em termos da massa de aplicação, lixiviação e acumulação (BRITO, 1999; LEITE; 1997). O balanço de massa foi calculado através da Equação (9):

Massa $_{\text {contam.retida }}=$ Massa $_{\text {Contam.(RSL bruto })}-$ Massa $_{\text {contam.(tratado })}$

Onde, MassaContam.retida é a massa do contaminante retida na matriz do cimento; Massa Contam. (RSL Bruto) é a massa do contaminante presente no RSL antes do tratamento em g; Massa Contam.(Tratado) é a massa do contaminante presente no material E/S após o tratamento em g.

\section{RESULTADOS E DISCUSSÃO}

\subsection{Caracterização do cimento Portland, RSL, areia e brita}

A concentração de sólidos totais obtida para o RSL foi de $87,57 \%$ e indica a quantidade total de matéria orgânica e inorgânica presente no resíduo. O teor de sólidos totais fixos do RSL foi de 79,0\%. Este valor indica que o resíduo sólido de laboratório apresenta elevada massa inorgânica a ser tratada. O teor de umidade do RSL foi de $12,43 \%$. Como o resíduo apresentou baixo teor de umidade, é considerado viável para o 
tratamento por E/S, tendo em vista que o excesso de água pode separar os agentes aglomerantes e dificultar as reações entre o RSL e os agentes solidificantes.

$\mathrm{O}$ pH do RSL apresentou valor 4,87 indicando a acidez do mesmo. A brita utilizada apresenta em sua constituição 99,98\% de sólidos totais, do teor de sólidos totais 99,90\% corresponde aos sólidos totais voláteis, indicando que a mesma é constituída basicamente por matéria orgânica. A areia apresentou teor de sólidos totais igual a 99,92\%, enquanto que a umidade apresentou $0,08 \%$.

O cimento utilizado apresentou teor de sólidos totais igual a 99,25\% e 98,97\% de sólidos totais fixos, esta quantidade elevada pode ser explicada por meio da composição química do aglomerante. O teor de umidade para o cimento foi inferior a $1 \%$. A baixa umidade do cimento é responsável pela facilidade com que ocorrem as reações químicas entre aglomerante e o RSL

\subsection{Classificação do cimento Portland, areia, brita e RSL}

Através do extrato lixiviado do resíduo sólido de laboratório observou-se que o Cádmio e o Níquel apresentaram valores superiores aos limites máximos permissíveis fixados pelas normas ABNT NBR 10.005 (2004b), ABNT NBR 10006 (2004c) e pela Companhia de Tecnologia de Saneamento Ambiental - (CETESB, 2005). O extrato lixiviado do RSL apresentou uma concentração do metal níquel de $193 \mathrm{mg} . \mathrm{L}^{-1}$ e de cádmio $109 \mathrm{mg} . \mathrm{L}^{-}$ 1.

Como pelo menos um dos parâmetros do RSL apresentou uma concentração maior do que a estabelecida pelos padrões máximos permissíveis, este pode ser classificado como resíduo perigoso, Classe I. Os mesmos são perigosos devido à toxicidade de acordo com a Norma NBR 10.0005 (ABNT, 2004).

\subsection{Avaliação da Integridade e Durabilidade dos Materiais E/S}

\subsubsection{Resistência à Compressão}

Os melhores valores de resistência à compressão foram obtidos para os tratamentos 01, 02 e 03, todos com tempo de cura de 28 dias e uma porcentagem de RSL igual a 10\%. 
Para os demais tratamentos realizados para 30 e 45\% de RSL, os resultados também foram satisfatórios, apresentando-se acima do limite mínimo permissível (1MPa) requerido para disposição em aterro sanitário.

Diante disto, o material obtido foi aprovado e pode ser descartado em aterro sanitário de forma segura e eficaz no que diz respeito a sua resistência. A referência maior que $1 \mathrm{MPa}$ foi sugerida por Brito (2007) no "Protocolo de Avaliação de Materiais Resultantes da Estabilização por Solidificação de Resíduos" e é o mesmo valor adotado na Holanda e na França para materiais E/S.

\subsubsection{Capacidade de Absorção de Água}

A partir dos ensaios de capacidade de absorção de água observou-se que à medida que se aumenta a porcentagem de RSL tem-se um aumento na capacidade de absorção de água para o tempo de cura fixo de 28 dias, possibilitando maior capacidade de lixiviar os contaminantes presentes no RSL.

Todos os resultados obtidos encontram-se em conformidade com a NBR 9778 (ABNT, 1987), os quais apresentaram porcentagem de absorção de água inferior a 40\%, indicando que o material E/S apresenta baixa porosidade favorecendo, desta forma, 0 controle da lixiviação dos contaminantes presentes no Resíduo Sólido de Laboratório para o meio.

\subsubsection{Umidificação/Secagem}

A partir deste ensaio observou-se que aumentando a quantidade de resíduo sólido de laboratório foram obtidas porcentagens superiores para U/S. Apesar disto, os corpos de prova preparados foram aprovados no presente ensaio, apresentando perda de peso inferior a 15\% após os períodos de umidificação/secagem.

\subsection{Análise de Lixiviação}

Todos os tratamentos realizados apresentaram concentração do metal pesado cádmio inferior ao limite máximo permissível $(0,5 \mathrm{mg} / \mathrm{L})$ recomendado pela ABNT NBR 
10.004 (2004), indicando que houve tratamento eficaz no que diz respeito a imobilização do cádmio presente no resíduo. Com relação ao metal pesado níquel todos os experimentos apresentaram concentração de níquel no extrato lixiviado acima do limite máximo permissível de 0,02 mg/L., no entanto, houve uma redução considerável deste metal, comparando com o resultado da lixiviação dos metais na sua forma bruta, que antes do processo de E/S era de $193 \mathrm{mg} / \mathrm{L}$ para o níquel.

Como a concentração do níquel presente no extrato lixiviado foi superior aos limites máximos permissíveis sugeridos pela CETESB, as matrizes cimentíceas obtidas foram reprovadas no critério de imobilização dos contaminantes, sendo classificadas como pertencentes à Classe I - Perigosos.

No entanto, observa-se que houve redução expressiva nas concentrações de níquel e cádmio comparando-se com os valores obtidos para o resíduo sólido de laboratório bruto, sem tratamento, que eram de $193 \mathrm{mg} / \mathrm{L}$ e $109 \mathrm{mg} / \mathrm{L}$, respectivamente.

\subsection{Análise estatística dos dados}

Para os ensaios de Resistência à Compressão (RC), Capacidade de absorção de água (CAA) e umidificação/secagem (U/S), a ANOVA apresentou valor de $P$ igual a 0,000 que é menor do que o nível de significância adotado $(0,05)$, com isto pode-se afirmar com 95\% de certeza que as médias dos tratamentos (10, 30 e 45\% de RSL) são diferentes entre si. Para os três ensaios, o valor de $\mathrm{F}$ calculado foi maior do que o $\mathrm{F}$ tabelado, desse modo, rejeita-se a hipótese numa $\left(\mathrm{H}^{0}\right)$ e o fator percentagem de resíduo sólido influenciou na variável resposta. Os três testes apresentaram a percentagem máxima explicável acima de $84 \%$, ou seja, mais de $84 \%$ dos dados foram explicados pelo modelo.

Para o teste de curvatura, o ensaio de $\mathrm{RC}$ e o ensaio de U/S apresentaram valor de $\mathrm{P}$ inferior a 0,05 , indicando que nestes casos há curvatura e o modelo a ser adotado foi 0 quadrático, pois, é o que proporcionou melhor ajuste dos dados. Para o teste de curvatura do ensaio de CAA, o valor de $P$ foi superior a 0,05 e o modelo a ser adotado foi o linear.

As equações 10, 11 e 12 apresentam o modelo adotado a partir da ANOVA para os ensaios de RC, CAA, U/S, respectivamente.

$\hat{\mathrm{Y}}_{R C}(\mathrm{MPa})=7,531-0,3167 \% \mathrm{RSL}+0,004396 \% \mathrm{RSL}^{2}$ 
$\hat{\mathrm{Y}}_{C A A}(\%)=6,956-0,02037 \% \mathrm{RSL}$

$\hat{\mathrm{Y}}_{U / S}(\%)=1,470-0,003395 \% \mathrm{RSL}-0,000482 \% \mathrm{RSL}^{2}$

Para os ensaios de lixiviação a ANOVA apresentou valor de $P$ igual a 0,000 que é menor do que o nível de significância adotado $(0,05)$, indicando que as médias são diferentes entre si. Para ambos os metais avaliados, o valor de $\mathrm{F}$ calculado foi maior do que o F tabelado. Deste modo, o fator percentagem de resíduo sólido influenciou na lixiviação dos metais pesados cádmio e níquel.

A percentagem máxima explicável ( $R^{2} \max$ ) ficou acima de $84,6 \%$ para ambos os metais avaliados. O restante que não pode ser explicado pelo modelo, são erros atribuídos à aleatoriedade do experimento. Para o ensaio de lixiviação do metal pesado cádmio, o teste de curvatura apresentou valor de $\mathrm{P}(0,296)$ maior do que 0,05 , então não há curvatura e o modelo a ser adotado deve ser o linear. Já para o ensaio de lixiviação do níquel, o valor de $\mathrm{P}(0,000)$ é menor que 0,05 . Então há curvatura e o modelo a ser adotado deve ser o quadrático, pois, é o que proporcionou melhor ajuste dos dados.

As equações 13 e 14 apresentam o modelo obtido para a regressão a partir da Anova para os ensaios de lixiviação do cádmio e níquel, respectivamente:

$\hat{\mathrm{Y}}(\mathrm{mg} / \mathrm{kg})=0,3032+0,005094 \% \mathrm{RSL}$

$\hat{\mathrm{Y}}(m g / \mathrm{kg})=2,912+0,06722 \% \mathrm{RSL}-0,002808 \% \mathrm{RSL}^{2}$

\subsection{Balanço de massa e cálculo da eficiência do processo de E/S}

$\mathrm{Na}$ Tabela 3, encontram-se os valores médios das massas do processo de E/S das matrizes cimentíceas de todos os tratamentos em relação ao cádmio presente no extrato lixiviado para obter o balanço de massa e eficiência do processo. 
Tabela 3 - Balanço de massa e eficiência do processo de E/S no extrato lixiviado do Cádmio

\begin{tabular}{|c|c|c|c|c|c|}
\hline Tratamento & \%RSL & $\begin{array}{l}\text { Massa do } \\
\text { Contam. } \\
\text { Bruto }^{1}(\mathrm{q})\end{array}$ & $\begin{array}{l}\text { Massa do } \\
\text { Contam. } \\
\text { Tratado }^{2}(q)\end{array}$ & $\begin{array}{c}\text { Massa do } \\
\text { Contam. } \\
\text { Retido }^{3} \text { (q) }\end{array}$ & $\begin{array}{c}\text { Eficiência de } \\
\text { Transformação } \\
(\%)\end{array}$ \\
\hline T1 & 10 & 212,63 & 1,97 & 210,66 & 99,97 \\
\hline T2 & 10 & 212,63 & 2,55 & 210,08 & 99,97 \\
\hline T3 & 10 & 212,63 & 2,56 & 210,07 & 99,97 \\
\hline T4 & 30 & 212,63 & 2,74 & 209,89 & 99,97 \\
\hline T5 & 30 & 212,63 & 2,94 & 209,69 & 99,96 \\
\hline T6 & 30 & 212,63 & 3,13 & 209,50 & 99,95 \\
\hline T7 & 45 & 212,63 & 3,11 & 209,52 & 99,96 \\
\hline T8 & 45 & 212,63 & 3,14 & 209,49 & 99,98 \\
\hline T9 & 45 & 212,63 & 3,13 & 209,50 & 99,96 \\
\hline
\end{tabular}

Nota: ${ }^{1}$ Massa do resíduo sólido bruto; ${ }^{2}$ Massa do contaminante tratado; ${ }^{3}$ Massa do contaminante retida na matriz; \%RSL: porcentagem de resíduo sólido de laboratório.

Fonte: Elaborado pelos autores.

Através da Tabela 3 pode-se observar que houve uma diminuição significativa na lixiviação do cádmio após a E/S, comparando-se com o resíduo sólido de laboratório bruto, sem tratamento (212,63 g que corresponde a concentração de $\left.109 \mathrm{mg} \cdot \mathrm{L}^{-1}\right)$.

O valor igual a 212,63 g de massa de resíduo sólido de laboratório significa a massa de resíduo a ser tratada. Deste total 210,66 g está retida na matriz de cimento e apenas $1,97 \mathrm{~g}$ foi lixiviada, ou seja, não está retida na matriz cimentícea. Para este tratamento (T1) a concentração de cádmio foi de $0,013 \mathrm{mg} \cdot \mathrm{L}^{-1}$, valor abaixo do LMP que é $0,5 \mathrm{mg} \cdot \mathrm{L}^{-1}$. Todos os tratamentos apresentaram eficiência de retenção média de aproximadamente 99,96\%, indicando que a $\mathrm{E} / \mathrm{S}$ foi um método eficaz no tratamento de resíduos sólidos de laboratório.

A Tabela 4 apresenta os valores médios das massas do processo de E/S das matrizes cimentíceas de todos os tratamentos em relação ao metal pesado níquel presente no extrato lixiviado para obter o balanço de massa e a eficiência do processo.

Tabela 4 - Balanço de massa e eficiência do processo de E/S no extrato lixiviado do Níquel

\begin{tabular}{|c|c|c|c|c|c|}
\hline Tratamento & $\% R S L$ & $\begin{array}{l}\text { Massa do } \\
\text { Contam. } \\
\text { Bruto }^{1}(\mathrm{~g})\end{array}$ & $\begin{array}{l}\text { Massa do } \\
\text { Contam. } \\
\text { Tratado }^{2}(\mathrm{~g})\end{array}$ & $\begin{array}{l}\text { Massa do } \\
\text { Contam. } \\
\text { Retido }^{3}(\mathrm{~g})\end{array}$ & $\begin{array}{c}\text { Eficiência de } \\
\text { Transformação } \\
(\%)\end{array}$ \\
\hline T1 & 10 & 376,50 & 19,75 & 356,75 & 99,88 \\
\hline T2 & 10 & 376.50 & 29.55 & 346.95 & 99.82 \\
\hline T3 & 10 & 376,50 & 29,38 & 347,12 & 99,82 \\
\hline T4 & 10 & 376,50 & 29,38 & 347,12 & 99,82 \\
\hline T5 & 10 & 376,50 & 29,41 & 347,09 & 99,81 \\
\hline T6 & 10 & 376,50 & 29,38 & 347,12 & 99,81 \\
\hline T7 & 10 & 376,50 & 33,06 & 343,44 & 99,79 \\
\hline T8 & 10 & 376,50 & 33,39 & 343,11 & 99,79 \\
\hline T9 & 10 & 376,50 & 33,33 & 343,17 & 99,79 \\
\hline
\end{tabular}

Nota: ${ }^{1}$ Massa do resíduo sólido bruto; ${ }^{2}$ Massa do contaminante tratado; ${ }^{3}$ Massa do contaminante retida na matriz; \%RSL: porcentagem de resíduo sólido de laboratório.

Fonte: Elaborado pelos autores. 
De acordo com a Tabela 4 observa-se que as médias dos tratamentos (T7, T8, e T9), por apresentarem maior porcentagem de RSL foram os que apresentaram menor massa de contaminante retida nas matrizes cimentíceas em relação as concentrações de níquel no extrato lixiviado, e, consequentemente apresentaram menor eficiência do processo de E/S. Pode-se concluir que a medida em que a quantidade de resíduo aumentou a capacidade de retenção do metal diminuiu.

Todos os tratamentos realizados para as diferentes porcentagens de Resíduo Sólido de Laboratório (10, 30 e 45\% de RSL) apresentaram concentrações de níquel superiores aos Limites Máximos Permissíveis que é de $0,02 \mathrm{mg} \cdot \mathrm{L}^{-1}$. No entanto, observou-se que houve redução bastante significativa na massa de níquel presente no material após o processo de E/S de 376,50 g para uma média de 29,62 g. O valor atenuado pode ser considerado satisfatório, pois, o níquel é um metal altamente perigoso e a sua atenuação é fator decisivo para disposição e gerenciamento adequado.

\subsection{Rotas de Destinação do RSL}

A partir dos resultados para os critérios de integridade/durabilidade e imobilização dos contaminantes, o Protocolo de avaliações proposto por Brito (2007) propõe várias rotas de destinação e/ou disposição dos materiais E/S. O material obtido apresentou todos os resultados dentro dos limites permissíveis para os ensaios de Resistência à Compressão, Capacidade de Absorção de Água e Umidificação/Secagem, sendo, portanto aprovado nos critérios de Integridade e Durabilidade para o material E/S.

Os resultados para os ensaios de lixiviação apresentaram valores abaixo dos limites máximos permissíveis recomendados para o metal pesado Cádmio. Em contrapartida, os resultados para os ensaios de lixiviação apresentaram valores acima dos limites máximos permissíveis recomendados para as concentrações de níquel, o que indica que o material obtido foi reprovado quanto ao critério de Imobilização dos Contaminantes.

A Tabela 5 apresenta a classificação dos materiais E/S com base nos resultados para os ensaios de Resistência à Compressão, Capacidade de Absorção de Água, Umidificação/Secagem e Lixiviação dos contaminantes Cádmio e Níquel a partir da análise do teor de metais pesados presentes nos extratos lixiviados das matrizes cimentíceas. 
Tabela 5 - Classificação dos Materiais E/S

\begin{tabular}{lllllll}
\hline \%RSL & RC & CAA & U/S & $\begin{array}{l}\text { Lixiviação } \\
\text { Cd }\end{array}$ & $\begin{array}{l}\text { Lixiviação } \\
\text { Ni }\end{array}$ & Classe \\
\hline $\mathbf{1 0} \%$ & Aprovado & Aprovado & Aprovado & Aprovado & Reprovado & Classe I \\
$\mathbf{3 0} \%$ & Aprovado & Aprovado & Aprovado & Aprovado & Reprovado & Classe I \\
$\mathbf{4 5 \%}$ & Aprovado & Aprovado & Aprovado & Aprovado & Reprovado & Classe I \\
\hline
\end{tabular}

Nota: RC: resistência a compressão; CAA: Capacidade de absorção de água; U/S: Umidificação e secagem; Casse I (Perigoso: ABNT NBR 10004/2004a);

Fonte: Elaborado pelos autores.

De acordo com os resultados para os testes de Integridade e Durabilidade e Imobilização dos Contaminantes apresentados na Tabela 5 foi possível definir uma rota de destinação para o material E/S. O material obtido deve ser encaminhado para a disposição em aterros específicos para Resíduos Perigosos, tendo em vista que foi reprovado nos ensaios de lixiviação conforme o Protocolo de Avaliação de Materiais E/S proposto por Brito (2007).

A norma NBR 10.157 (ABNT, 1989) regulamenta a disposição de resíduos perigosos e com características tóxicas em células especiais de disposição com o objetivo de proteger as áreas localizadas próximas à disposição de materiais que apresentem características contaminantes Segundo Barth et al. (2010) os objetivos da E/S consiste em melhorar o manuseio e as características iniciais do resíduo, além de reduzir a massa do contaminante no material final obtido.

\section{CONCLUSÕES}

O resíduo avaliado permaneceu na Classe I (Perigoso), no entanto, todos os tratamentos realizados apresentaram eficiência de retenção dos metais pesados cádmio e níquel acima de $98 \%$. Nesta pesquisa, a redução (comparada às suas concentrações no resíduo bruto) na concentração de ambos os metais avaliados, cádmio e níquel, confirma que eles sofreram algum mecanismo de imobilização efetivo na matriz de cimento, apesar de alguns dos tratamentos realizados ainda apresentarem concentrações dos metais superiores aos Limites Máximos Permissíveis recomendados, indicando que a estabilização/solidificação é uma opção viável para atenuar a quantidade de metais pesados presentes em resíduos sólidos de laboratórios químicos. 


\section{REFERÊNCIAS}

ABNT - ASSOCIAÇÃO BRASILEIRA DE NORMAS TÉCNICAS. NBR 9778: Argamassa e concreto endurecidos - determinação da absorção de água por imersão - índice de vazios e massa específica. Rio de Janeiro: ABNT, 1987.

ABNT - ASSOCIAÇÃO BRASILEIRA DE NORMAS TÉCNICAS. NBR 11578: Cimento Portland composto: especificações, Rio de Janeiro: ABNT, 1991.

ABNT - ASSOCIAÇÃO BRASILEIRA DE NORMAS TÉCNICAS. NBR 7211: Agregados para concreto - especificação. Rio de Janeiro: ABNT, 2009.

ABNT - ASSOCIAÇÃO BRASILEIRA DE NORMAS TÉCNICAS. NBR 10.157: Aterro de resíduos perigosos: critérios para projeto, construção e operação. Rio de Janeiro: ABNT, 1987a.

ABNT - ASSOCIAÇÃO BRASILEIRA DE NORMAS TÉCNICAS. NBR 7215: Determinação da resistência à compressão do Cimento Portland. 1. ed. Rio de Janeiro: ABNT, 1996.

ABNT - ASSOCIAÇÃO BRASILEIRA DE NORMAS TÉCNICAS. NBR 10.004: Classificação de resíduos. Rio de Janeiro: ABNT, 2004a.

ABNT - ASSOCIAÇÃO BRASILEIRA DE NORMAS TÉCNICAS. NBR 10.005: Lixiviação de resíduos - procedimento. Rio de Janeiro: ABNT, 2004b.

ABNT - ASSOCIAÇÃO BRASILEIRA DE NORMAS TÉCNICAS. NBR 10.006: Solubilização de resíduos - procedimento. Rio de Janeiro: ABNT, 2004c.

APHA. Standard methods for the examination of water and wastewater. 20th Edition, Washington DC: American Public Health Association, American Water Works Association and Water Environmental Federation, 1998.

AQUIM, P. M. Gestão em curtumes: uso integrado e eficiente da água. 2009. 159f. Tese (Doutorado em Engenharia Química) - Universidade Federal de Campina Grande. Campina Grande - Paraíba, 2009.

BARTH, O.M.; FREITAS, A.S.F.; OLIVEIRA, E.S.; SILVA, R.A.; MAESTER, F.M.; ANRELLA, R.R.S.; CARDOZO, G.M.B.Q.Evaluation of the botanical origin of commercial dry bee pollen load batches using pollen analysis: a proposal for technical standardization. Anais Bee pollen loads from southern Brazil, v. 82, p. 893-902, 2010. https://doi.org/10.1590/S0001$\underline{37652010000400011}$

BREHN, F. A.; KULAKOWSKI, M.P.; EVALDT, D.C.; MORAES, C.A.M.; PAMPANELLI, A.B.. Análise da estabilização por solidificação de lodo de fosfatização em matrizes de cimento Portland e de cerâmica vermelha para a utilização na construção civil. Ambiente Construído, Porto Alegre, v. 13, n. 2, p. 15-27, abr./jun. 2013. https://doi.org/10.1590/S1678-86212013000200003

BRITO, A. L. Protocolo de avaliação de materiais resultantes da estabilização por solidificação de resíduos. 2007. 179 f. Tese (Doutorado) - Curso de Engenharia Ambiental, Universidade Federal de Santa Catarina, Florianópolis, 2007. 
BRITO, A.L.F.; SOARES, S. R. Avaliação da integridade e da retenção de metais pesados em materiais estabilizados por solidificação. Eng. Sanit. Ambient. v.14, p. 39-48, 2009.

http://dx.doi.org/10.1590/s1413-41522009000100005

BRITO, A. L. F. Codisposição de resíduos sólidos urbanos e resíduos sólidos de indústria de curtume. Campina Grande: UFPB/UEPB, 1999.

CETESB. COMPANHIA DE TECNOLOGIA DE SANEAMENTO AMBIENTAL. Decisão de diretoria no 195-2005-E, de 23 de novembro de 2005.

CHEN, L.; WANG, L.;CHO, D.W.; TSANG, D. C.W.; TONG, L.; ZHOU, Y.; Y,J.; HU,Q.; POON, C.S.. Sustainable stabilization/solidification of municipal solid waste incinerator fly ash by incorporation of green materials. Journal of Cleaner Production, v. 222, n. 10, p. 225-343, jun, 2019. https://doi.org/10.1016/j.jclepro.2019.03.057

IMBROISI, D.; SANTOS, A. J. M. G.; BARBOSA, S. S.; SHINTAKU, S. F.; MONTEIRO, H. J.; PONCE, G. A. E. P.; FURTADO, C. J. T.; MELLO, D. C. Gestão de resíduos químicos em universidades: universidade de brasília em foco. Química Nova, São Paulo, v. 29, n. 2, p.404409,2006. https://doi.org/10.1590/S0100-40422006000200037

LEITE, C.B.B. Aspectos metodológicos no estudo e caracterização de contaminação de solo e água. In: WORKSHOP SOBRE ÁREAS CONTAMINADAS. São Paulo, 1997. Resumos Expandidos [...] CETESB/GTZ/USP, p. 35 - 6, 1997.

LIMA, A.; MATIAS, A.; SOBRINHO, I. Produção dos resíduos químicos nos laboratórios do instituto multidisciplinary em saúde da Universidade Federal da Bahia (IMS/UFBA) no período de 2011 à 2014. REPOSITÓRIO Institucional. UFBA. 2016.

https://repositorio.ufba.br/ri/handle/ri/19232?mode=full\&submit simple=Mostrar+registro+completo + do+item

LOZOVEY, L.R. Diagnóstico do sistema de gerenciamento dos resíduos de construção e demolição (RCD) no município de Florianópolis e seu enquadramento no cenário atual. 2014. Trabalho de Conclusão de Curso. (Graduação) Florianópolis, SC. Disponível em: https://repositorio.ufsc.br/bitstream/handle/123456789/124961/TCC\%2BLuisa para\%2BCD\%2Bfin al.pdf?sequence $=1 \&$ isAllowed $=y$

MINITAB INC. Statistical software: data Analysis Software. Version 17, 2017.

MONTGOMERY, D. C.; RUNGER, G. C. Estatística aplicada e probabilidade para engenheiros. 2. Ed. São Paulo: LTC Editora, 2003.

RAMOS, F. M. S.; KAMINATA, O. T.; TAVARES, C. R. G.; BENATTI, C. T.; CAPELASSO, M.; INNOCENTI, B. D. Avaliação da técnica de solidificação/estabilização no tratamento de resíduo têxtil - produção de bloco cerâmico de vedação. Cerâmica, v. 55, p. 408 - 414, 2009.

https://doi.org/10.1590/S0366-69132009000400011. Disponível em:

https://www.scielo.br/pdf/ce/v55n336/11.pdf.

SCHNEIDER, V.T. Gerenciamento de resíduos no centro universitário UNIVATES. 2014. 44f. Monografia. Curso Técnico em Química. Lajeado, RS. Disponível em:

https://silo.tips/download/gerenciamento-de-residuos-no-centro-universitario-univates 
WANG, Y.S.; DAI, J.G.; WANG, L.; DANIEL, C.W.T.; POON, C.S.. Influence of lead on stabilization/solidification by ordinary Portland cement and magnesium phosphate cement. v. 190, p. 90-96, Jan. 2018. https://doi.org/10.1016/j.chemosphere.2017.09.114 